\title{
부산총회 이후 민간부문의 역할
}

\author{
정 진 규 주OECD 대표부 참사관
}

\section{목 차}
I. 민간분야의 중요성 부각
II. 부산 민 - 관 공동성명서의 의미
III. 우리나라 개발정책에 대한 함의

\section{I. 민간분야의 중요성 부각}

부산세계개발원조총회(HLF-4, 이하 부산총회)는 글로벌개발커뮤니티가 매우 중요한 몇 가지 새로운 주 제를 다루는 계기가 되었다는 점에서 그 외형적인 성공1)에 못지않은 역사적인 의미를 가지고 있다고 하겠 다. 개발효과성 추구, 글로벌 파트너십, 개도국 중심의 개발전략 수립 등 많은 새로운 주제가 제시되었으며, 이에 대한 활발한 토론과 이행방안이 구체적으로 논의되었다. 그 중 국제개발협력 커뮤니티가 관심을 기울 이고 있는 가장 두드러진 주제 중 하나는 개발협력에 있어서 '민간분야의 부상'이라고 할 수 있을 것이다.

불과 수 년 전까지만 해도 개발협력 또는 개발원조는 공적개발원조(이하 ODA)2)를 지칭하는 말로 인식 되어 왔으며 이 과정에서 민간분야의 대 개도국 협력은 상당부분 간과되어 온 경향이 있다. 그러나 2010 년경부터 $\mathrm{OECD}$ 개발원조위원회(이하 $\mathrm{DAC}$ )과 원조효과작업반(WP-EFF)3)을 중심으로 비교적 새로운 이 슈인 "개발효과성(development effectiveness)", "포괄적 개발협력(inclusive development cooperation)" 이 본격적으로 논의되면서 자연스럽게 공적개발원조 또는 원조(aid)개념의 한계와 이를 보완하기 위한 민 간부문 역할 강화 필요성이 투자, 무역을 위한 원조, 성장, 국내재원동원 등 분야를 중심으로 제기되었다.

1) 부산총회는 10 여명의 최고위급 인사, 100 명 이상의 장관급 인사, 40 여명의 국제기구 수장, 70 여개 국제기구 대표를 포 함, 정부, 시민사회, 의회, 민간분야 대표 등 160 여개국에서 3,000 여명이 참석

2) Official Development Assistance로 DAC 이 그 개념을 정하고 있다. 2009년부터 정부(공공기관 포함)의 개발원조재원만을 통 계에 포함하는 것은 한계가 있다는 지적이 본격적으로 나오면서 동 개념의 재정의 또는 수정 방안이 DAC에서 나오고 있다.

3) 2005년 파리선언(Paris Declaration on Aid Effectiveness)과 2008년 아크라행동계획(Accra Agenda for Action)을 도출 해 내고, 2011년 부산 세계개발원조총회에서 '부산선언(Busan Partnership for Effective Development Cooperation)'을 만들어 낸 DAC의 산하조직. 2011년 맨데이트 기간 연장으로 2012 6월까지 존속할 예정이다. 
특히 DAC 회원국 정부의 개발원조 재원이 그 효과성4)과 규모5)면에서 모두 한계와 문제점을 노정 하게 되면서, 민간분야는 개도국 개발결과(development result)를 지속적으로 증진시켜 줄 동력이라 는 기대가 크게 증가하였다. 민간분야의 대 개도국 협력은 그 규모와 성장지향성 측면에서 그 중요성 이 증대하고 있으며, 기존 $\mathrm{ODA}$ 를 보완하면서 개도국의 경제성장을 이루어 나갈 수단으로 인정되고 있는 바, 특히 다음과 같은 세 가지 측면이 부각되고 있는 것은 주목할 만하다.

첫째, 민간분야 개도국 협력 재원은 규모면에서 공여국 정부가 제공하는 재원인 ODA를 압도하고 있 는데 대개 그 규모가 ODA의 약 3 4배에 달하는 정도인 것으로 알려져 있다. 비록 민간분야 재원규모는 경기에 따라 변동성이 상대적으로 크다는 단점은 있으나 그 절대규모로 보면 2007년 4,500억불(ODA의 4 배), 2009년 3,800억불(ODA의 3 배)을 기록, ODA에 비해 훨씬 큰 재원 동원능력을 보여주고 있다.

\section{표. DAC 회원국의 개도국에 대한 개발재원 흐름 총계}

\section{Figure B.1. DAC members' total net resource flows to developing countries (1970-2009)}

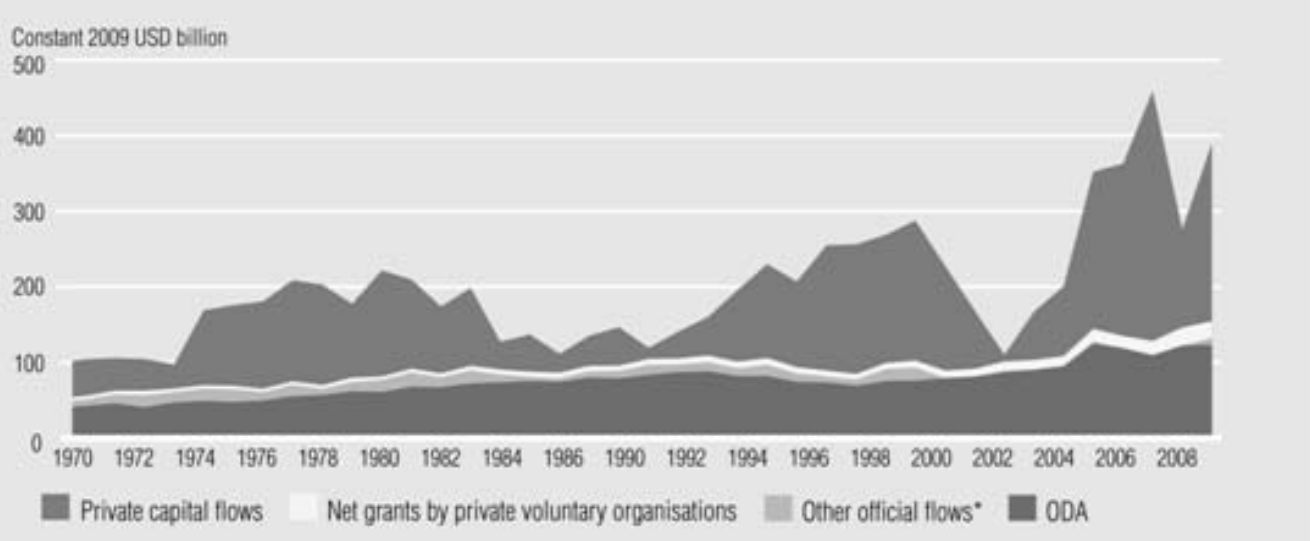

둘째, 민간분야는 고용창출, 기술혁신, 기업가 정신 등을 확대함으로써 개도국의 실질적 발전과 성 장을 유도할 가능성이 매우 높다고 평가된다. 개도국과 민간분야의 연계는 여러 가지 형태가 있을 수 있으나, 투자, 능력배양(capacity building), 포괄적인 비즈니스모델, 지식공유(knowledge sharing), 혁신(innovation)추구 등이 대표적인 유형이다.

4) Moyo는 Dead Aid에서 아프리카에 대한 공여국 정부의 원조가 동 국가(지역)의 발전 또는 성장에 거의 효과가 없거나 부정적 영향을 끼친다는 점을 지적함.

5) 비록 2009년 이래 DAC회원국의 ODA는 매년 그 기록을 갱신하고 있으나(2010년 약 1300억불) 그 절대적 규모는 지원 대상 개도국의 원조재원 수요 및 동 국가들의 경제규모에 비추어 상대적으로 미약한 수준이라는 평가가 많다. 
이러한 인식에 기초하여 종전 개도국과 공여국 정부차원의 개발협력에 초점을 맞추었던 DAC 주도의 일련의 원조효과성에 관한 고위급회의(High Level Forum on Aid Effectiveness)6)는 2011년 부산총회 에서 비로소 민간분야의 본격적인 개발협력 참여를 인정하고 새로운 공공민간협력(public-private cooperation)플랫폼 구축방안 모색에 합의하였다. 이와 함께 부산총회 결과문서에서는 효과적인 개발 을 위한 협력 증진의 일환으로 민간분야 역할의 중요성을 인정하는 한편 민간분야의 개발 및 성장 (growth) 관련 정책형성 참여, 민간의 역할을 지원하는 제도적 환경 마련 등이 포함되었다.

셋째, 포괄적 개발 개념이 중시되면서 개도국에서의 개발임팩트를 제고하는데 있어서 가장 중요한 요 소 중 하나가 민간부문이라는 인식이 강해졌으며, 이와 관련 천년개발목표(MDGs)의 맥락에서 부산총회 결과문서에 포함된 민간분야의 역할과 행동계획을 구체화시키는 것이 중요한 과제로 제기되고 있다.

한편 민관파트너십의 원조효과성 제고에 대한 기여측면에 대해서도 관심을 기울일 필요가 있는 바, 기본적으로 이윤추구가 지상목표인 민간기업이라는 새로운 주체의 개입으로 인해 개발원조 측면 에서 복잡성과 거래비용을 증가시키는 요인이 될 수 있다는 점에 유의해야 할 것이다. 따라서 기업의 이윤추구방식과 개도국의 개발관점을 결합시킴으로써 민관파트너십을 통한 개발효과 제고 및 개도국 에서의 기업활동 지속성 유지를 동시에 모색해야 한다는 견해가 제시7)되고 있다.

이와 같은 '민간부문'에 대한 정책적 관심의 증대와 구체적 이행계획 필요성에 대한 인식강화는'원 조'를 넘어 전체적인 발전과 성장을 추구한다는 글로벌 개발커뮤니티의 논의를 반영하는 동시에 개 도국의 개발성과 및 개발임팩트를 극대화하기 위한 전략으로서 민간부문의 연계 이슈를 글로벌 개발 커뮤니티가 핵심 의제의 하나로 도입하기 시작했다는 의미로 해석된다.

\section{II. 부산 민 · 관 공동성명서의 의미}

\section{5 대 기본원칙}

부산총회에서 정부, 민간, 다자 및 양자개발협력기관의 대표들은 부산 민 관 공동성명서(이하 공동성 명서) 8 를 채택하였는데, 동 공동성명은 개발분야 민 관 공동협력에 관한 최초의 선언문서라는 점에 의

6) 2002년 로마, 2005년 파리, 2008년 아크라, 2011년 부산의 네 차례 고위급회의(HLF)를 개최하였으며, OECD 개발협 력국(DCD)이 그 사무국을 맡아 왔다.

7) 일본의 경우 이러한 측면을 고려한 BOP(Bottom of Pyramid) 사업 추진 필요성 등이 논의되고 있다.

8) 발표된 성명서의 영문명칭은 "Expanding and Enhancing Public and Private Co-operation for Broad-based, Inclusive and Sustainable Growth -A joint Statement for endorsement by representatives from public and private 
미가 있다. 이번 성명서에 대한 합의를 계기로 정부와 민간부문은 아래 다섯 개의 원칙9)을 중심으로 개 발정책 수립 및 이행에서의 협력 플랫폼 구축을 포함한 제반 후속조치를 마련해 나갈 것으로 예상된다.

\section{1) 지속가능한 발전을 가능케 할 환경조성을 위한 포괄적인 대화}

정부, 특히 개도국 정부가 발전이 일어날 수 있는 환경을 조성하기 위해 국내 및 해외 민간분야와 긴밀히 협의해야 한다는 원칙으로 개도국 개발계획 수립 및 경제운용에 있어서 민간분야의 참여가 필요하다는 측면을 강조하고 있다. 즉 개도국 정부의 투자환경 조성, 전략적 산업의 육성이 실질적인 발전지향성을 갖기 위해서는 결국 이러한 환경조성에 직접적인 영향을 받게 되는 민간분야와의 긴밀 한 협의가 필요하다는 점을 강조하고 있다.

개도국의 지속적 발전을 가능하게 하는 정책환경의 조성은 주로 해외투자기업을 비롯한 민간분야의 적극적인 개도국 시장 및 산업분야에 대한 참여를 확대하기 위한 기반이 되는데 사회안정 및 신변안 전, 법치주의, 인권보장의 강화, 책임성과 투명성이 보장되는 거버넌스, 부패척결, 경제·사회 인프라 조성, 안정적이고 예측가능한 경제정책, 교육받은 노동력, 명확한 소유권(property rights) 규정 및 사적계약의 보장, 자국 민간기업의 경쟁력 강화, 형평성이 기반이 된 성장 등이 핵심요소로 거론된다.

이와 함께 개발친화적인 법적, 정책적 프레임워크의 구축, 규제매커니즘의 구비, 개도국 민간분문 의 기술 및 능력강화, 금융서비스에 대한 접근성 개선 등이 필요하며 규제완화, 인센티브 창출, 여성 의 기업활동 참여지원, 기업의 사회적 책임성 강화, 자원 및 에너지의 효율성 강화 기반 구축, 녹색성 장 전략의 도입 등도 중요한 제도적 검토이슈가 될 것이다. 한편, 개도국 원조와의 관련성 역시 중요 하게 검토할 필요가 있는 바, 원조를 민간기업의 투자를 더욱 확대시키기 위한 레버리지로 활용하는 방안, 민간재원이 부족한 빈곤국가에서 초기 투자위험을 원조를 통해 분산시킴으로서 민간기업의 후 속투자를 유발하는 방안, 양허성 재원인 ODA와 민간상업자금을 혼합하여 시장의 비즈니스 수요에 부 합하게 만드는 방안 등을 다각적으로 분석하여 최적의 개발친화적 정책환경을 조성할 필요가 있다.

\section{2) 공동행동의 실행}

금번 부산총회에서 민·관협력이 실행되기 위해서는 개도국의 국내 및 글로벌 차원에서 정부와 민 간이 소통하고 의견과 정책을 조율하기 위한 반영구적 플랫폼이 필요하다는데 공감대가 형성되었다 는 점은 매우 중요한 진전10)이다. 공동성명서에서 국가발전 계획 또는 각 산업분야별 발전계획 수립

sector at the Fourth High-Level Forum on Aid Effectiveness" 임.

9) 5 개의 원칙(영문)은 (1) Inclusive dialogue for building a policy environment conducive to sustainable development

(2) Collective action (3) Substantiality (4) Transparency (5) Accountability

10) 이는 민관협력에 있어서 최초의 합의이며, 과거 개발분야에서 양측의 협력과 의견을 조율할 상시적 매커니즘은 존재하 
과정에서 민간분야와의 대화는 매우 중요한 필수전제 조건으로 이해되고 있으며 포괄적 성장과 경제 적 기회확대를 도모하는데 있어서 민간분야와 정부의 공조에 대한 중요성이 강조되고 있다.

민관협력 과정에서 다양한 규모의 민간기업과 함께 정부, 관련 기관 등을 연계시키는 포괄적인 가 치사슬 방법론(broader market and value chain development approaches) 도입은 민간분야와 정 부간 공조를 통해 민관협력의 임팩트 제고를 추진하는 적절한 방안 중 하나가 될 수 있을 것이다.

이러한 측면에서 볼 때 상시적 정책협의 플랫폼은 개도국 정부주도로 민관 경제계획 자문회의, 민 관 공동작업팀 등 다양한 형식으로 조성될 수 있으며(개도국 레벨), $\mathrm{OECD}$ 나 유엔 등 국제기구 주도 로'글로벌 민관개발 파트너십 회의’ 등의 형태로 설치(글로벌 레벨)될 수 있을 것이며 양자는 상호보 완적인 관계를 설정하면서 다양한 레벨에서 정부와 민간분야의 공동행동을 구체화시켜 나가는데 기 여할 것으로 기대된다.

\section{3) 지속가능성}

민관협력이 개발분야에서의 성과를 지속적으로 도출해 내기 위해서는 민관협력 활동이 국내법 및 국제 규범을 준수해야 하며, 해당 개도국의 정책 우선순위와 체제능력에 부합해야 할 것이다. 민관협력은 대부 분 상업적 고려가 포함되어 있으며 기업간 이해관계, 기업차원에서의 이익 극대화를 위한 고려 등이 반영 되게 되므로 국내외적으로 합의된 규범에 따르지 않을 때 그 활동이 개도국의 지속적 발전과 개도국 오너 십을 저해할 가능성도 배제할 수 없는 바, 민관협력 활동이 지속적으로 개발임팩트를 가지도록 하기 위해 서는 국내법 및 국제규범에 대한 존중이라는 원칙을 견지해야 한다는데 대한 공감대가 조성되고 있다.

\section{4) 투명성}

민관협력에 있어서 상업적투명성 확보는 매우 중요한 요소가 된다. 투명성의 증진과 예측가능한 제도적 환경은 개도국의 경제성장을 이루어 내기 위한 기업활동의 전제조건이 되며 개방경제의 기본 적 요소가 된다. 이러한 측면에서 개도국의 투명성 분야는 현재 국제사회에서 진행되고 있는 투명성 및 책임성 이니셔티브11)를 포함시켜 외국(주로 공여국)의 민간기업들에게 보편적인 행위의 기준을 제시하는 것이 필요할 것으로 보인다.

한편, 동 투명성 원칙은 개도국 정부에만 요구되는 것이 되어서는 안되는 것임을 자명하다. 민간 기업 역시 자원채굴, 고용 등 개도국에서의 기업활동과 관련된 정보와 자료를 일정 범위에서 투명하

지 않았다.

11) 공동성명서는 동 이니셔티브의 예로 the Extractive Industry Transparency Initiative (EITI), the Natural Resource Charter, the Kimberly process, the Forest Law Enforcement, Governance and Trade(FLEGT) initiative and the Construction Sector Transparency Initiative를 들고 있다. 
게 제공함으로써 상호적 투명성을 확보하는데 협조하여야 한다는데 대한 공감대가 형성되고 있다.

투명성의 제고를 위해 수집정보의 질 제고, 개발임팩트에 미치는 주요한 정보 및 통계(민간원조재원, 해외 송금, 해외직접투자 등)에 확보, 반부패 및 뇌물방지 노력 제고, 광물자원 등에 대한 관리 강화, 인프라 사업 추진시 정부조달(government procurement)과정에 대한 투명성 제고 노력에 대한 지원강화 등이 필요할 것 이며, 이에 관한 구체적인 규범 논의는 $\mathrm{OECD}, \mathrm{UN}, \mathrm{G} 20$, Kimberly process 등을 중심으로 전개되고 있다.

\section{5) 결과에 대한 책임성}

민관협력의 결과(성과)를 정확히 모니터링하고 모니터링 결과를 보고, 평가하는 것은 개발결과의 책임성 또는 상호책임성 확보에 있어서 매우 중요하다. 특히 지속가능한 민관협력 파트너십의 결과 의 모니터링·평가를 부산결과문서에 포함된 Post-Busan 이행체제와 연계하여 추진함으로써 상호보 완성과 시너지 효과를 제고할 수 있을 것으로 예상된다.

다만 현재 $\mathrm{OECD}$ 를 비롯한 관련 국제기구가 민간분야의 개도국 관련 활동과 관련된 자료를 축적하 거나 평가지표 개발, 모니터링 등을 수행한 경험이 없고, 동 결과측정의 대상이 되는 기업의 범위 등 이 정의되어 있지 않은 점을 감안할 때, 이에 대한 정부· 민간분야 간 추가적인 합의도출이 필요할 것 으로 예상된다.

\section{2. 후속조치 계획}

민간분야의 개발참여 이슈는 부산총회 결과문서의 근간을 이루는 “빌딩블럭”중의 하나로서 각국 정부, 민간기관의 자발적인 참여 및 리더십에 의하여 새로운 정부-민간분야 간 협력프로세스를 만들어 내는 것을 목표로 하고 있다. ${ }^{2)}$ 원칙적으로 정부와 민간기관의 자발적 참여를 기초로 정부-민간기업간 비공 식적 정보공유 활성화를 위한 정책대화 플랫폼 설치 추진방안을 마련하는 것으로 $\mathrm{OECD}$ 사무국, $\mathrm{OECD}$ $\mathrm{BIAC}, \mathrm{UN}$ 글로벌컴팩트(UNDP), 국제상공회의소(ICC) 등 관련 국제기구들간 협력이 요청된다.

공동성명의 이행은 Post-Busan 이행의 전체적인 맥락에서 추진되어야 하는 것으로 정해진 기간 내에 포괄적인 정부-민간간 협력방안을 도출해야 하며, 이 과정에서 기존의 민관협력을 위한 제도나 네트워크 보완하는 방식으로 추진되어야 한다.

12) 공동성명서에서 2012년 6월까지 제안서를 마련하기로 합의하였다. 
금번 부산총회에서 민관협력의 중요성이 부각됨에 따라 민관협력 논의의 중심 포럼에 대한 논의가 예상되는 바, 원조효과작업반의 상위기관으로서 $\mathrm{DAC}$ 이 민관협력방안을 논의할 적절한 포럼인가에 대해서는 다양한 의견이 제시 될 수 있을 것이다. 그러나 DAC은 글로벌차원에서의 민관협력 논의를 주도하는데 있어서 많은 장점을 가지고 있는 바, $\mathrm{DAC}$ 이 민관협력에 대한 정책방향 논의 (Post-Busan 포함)의 중심적 포럼이 될 수 있을 것이다. DAC의 장점을 살펴보면, 첫째, DAC은 파 리선언, 아크라행동계획 등 글로벌개발원조의 규범 설정, 지표수립, 이행 가이드라인 마련 등에 있어 서 중심역할 을 수행해 왔으며, 둘째, DAC은 이미 다수의 민관협력 기준과 규범13)을 수립하여 제시 한 바 있으며, 셋째, $\mathrm{DAC}$ 은 $\mathrm{OECD}$ 의 광범위한 정책분야별 전문성과 네트워크를 충분히 활용할 수 조직측면의 장점을 가지고 있다는 점을 들 수 있다. 다만 DAC의 제한된 회원국, 개도국 현지 차원의 민간기업에 대한 접근성 취약, 집행기능 부재 등 문제점은 UNDP와의 공조, $\mathrm{OECD} \mathrm{BIAC} \mathrm{등} \mathrm{민간네}$ 트워크와의 적극적인 연계 등을 통해 보완되어야 할 사항들이다.

\section{3. 글로벌 개발정책 맥락에서의 의의}

금번 부산총회시 채택된 공동성명서는 민간부문과 정부의 이행과제를 제시하는 등 실천을 위한 구체적 인 액션플랜을 제시하고 있다는 점에 그 특징이 있다고 하겠다. 특히 모든 개발재원 흐름에 대한 투명한 정보 제공, 개발친화적 제반 환경조성(building an enabling environment), 각 개도국의 개발맥락에의 민간분야 통합, 공공-민간간 파트너십 확대에 대한 정부, 민간부문의 역할과 조치내역을 예시적으로 열 거함으로써 향후 Post-Busan 프로세스에서 민관협력을 통해 추진할 작업방향을 제시14)하고 있다.

공동성명서는 공약(commitment)이 아닌 “공동행동(joint action)"을 목표로 하고 있는 바, 5가지 공통 의 원칙(Five Shared Principles)을 제시하고 있으나, 민간분야의 특수성을 감안하여 차별적으로 적용되 는 대등한 파트너십(equal partnership)을 기초로 한 공동행동 원칙이라는 특징을 갖는다고 하겠다.

이러한 맥락에서 민관정책대화 플랫폼 설치방향은 각 세부분야별 선도적 주체(best champions)를 발굴15)하고 모범사례를 공유, 확산해 나가는 것이 될 것으로 예상된다. 선도적 주체선정과 모범사례 발굴이 필요한 분야는 주로 인프라구축, 개발친화적 환경조성, 고용증진, 농업 및 식량안보, 보건이 슈, 투명성 분야 등이 될 것으로 보인다16). 아울러 개발을 위한 효과적인 파트너십 구축을 위한 보건

13) 이러한 예로 "Policy Framework for Investment", "the OECD Guidelines for Multilateral Enterprises", "the OECD Principles for Private Sector Participation in Infrastructure", "Public-Private Dialogue in Developing Countries", "the OECD Guidelines Due Dilligence Guidance for Responsible Supply Chains of Minerals from Conflict and High Ri나 Areas" 등이 있다.

14) 이는 공동성명서 부속서(ANNEX 1, ANNEX 2)에 포함된 내용이다.

15) 현재 거론되고 있는 분야별 Private Sector Champions(예시)는 (1) Agriculture/Food Products: Pepslco, Kraft, Dupont, Coca-Cola, DSM, Unilever, TNT, Friesland Campina, Rabobank, Heineken etc. (2) Natural Resources: Chevron (3) Finance: JP Morgan Chase, Goldman Sachs, Standard Bank in Africa etc. (4) Health: Pfizer, Merck 등이 있다. 
분야 민관정책대화 활성화, 민간투자 확대를 유도하기 위한 인프라환경 개선, 금융접근성 확대를 위 한 국제금융기관과 개도국 정부와의 파트너십 형성, 무역과 투자분야에서의 제도개선 등도 개발을 위한 효과적인 파트너십의 일환으로 거론된다.

또한 동 공동성명서 이행과정에서 민간분야의 기여를 활성화하고 지원하기 위한 ODA 역할 강화 및 보증, 위험분산 등을 위한 다양한 지원매커니즘 마련 필요성도 충분히 반영되어야 하며 교훈의 선 별 필요성, 경제성장, 고용, 빈곤감소 측면에서 글로벌 민간분야 Value chain의 중요성 등도 고려되 어야 할 것이다.

민관협력의 개발 및 원조효과성 제고에 대한 효과를 극대화하기 위해서는 민관협력 프로세스 작동 을 지원하기 위한 균형잡힌 지지기반의 확충, 개발성과 달성을 위한 관점의 확대(원조에서 개발로), 변화하는 글로벌 개발체제(development architecture)에 부합한 민간기업의 역할에 대한 합의도출 이 필요할 것이다. 이와 함께 지속적인 민간분야의 개도국 개발에 대한 참여를 위해 인센티브의 발굴 및 강화가 요청된다.

특히 종래 민간기업, 정부, NGO 등 서로 다른 행위자들에 대한 이해관계의 조율, 상호간 신뢰형성, 기업의 이윤활동과 개도국 발전목표와의 부합성 제고를 위해 공유된 행동규범이 필요하다는 지적이 많았음에도 불구하고 이에 대한 구체적인 합의문서가 제시되지 못한 문제점이 있었다. 이러한 측면에 서 볼 때 금번 부산 공동성명서 채택은 글로벌 개발커뮤니티가 민관협력을 확대하기 위한 공유된 행동 규칙 수립과 대화 플랫폼 구축을 본격화했다는 점에서 큰 의의를 가진다고 할 수 있을 것이다.

이에 덧붙여 공동성명서에서 글로벌개발커뮤니티가 민간부문을 최초로 정부와 동등한 지위를 가 진 중요한 개발파트너로 인정한 점, 개발친화적 환경 조성의 양대 주체로 정부와 민간부문을 규정한 점 등은 향후 개발협력에 있어서 민간부문의 역할 강화를 시사하는 중요한 부분이라고 할 수 있다.

다만 여전히 현재 민관협력의 개념이 상당부분 모호하여 보다 명확한 정의가 필요하다는 지적도 많이 제기되고 있는 바, 이러한 측면에 대한 보완책도 마련되어야 할 것이다. 특히 "개발에 대한 민 간기업의 기여"는 CSR(Corporate Social Responsibility), 사회적 기업(Social Enterprise), Fair Trade, PPP(Public Private Partnership), PPC(Public Private Cooperation) 등 상대적으로 협의의 개념에서부터 FDI, 산업시설 이전, 다국적 기업의 현지진출 등 일반적인 비즈니스 활동까지 광범위 하게 포함될 수 있는 바, 민관협력 방안에 대한 보다 실질적인 논의를 위해서는 논의대상의 범위와 대상을 보다 명확하게 정할 필요가 있을 것이다.

16) Busan HLF-4 Parallel Session(Private Sector) Concept Paper(OECD 사무국 내부문서) 참조 
이와 함께 지적되는 문제점은 금번 공동성명서에 참여한 중소기업(SMEs)과 개도국의 숫자가 매우 제한적이어서 동 공동성명서의 실질적 이행이 제약될 수 있다는 측면과 공통원칙에 대한 이행매커니 즘이 상당히 불투명한 상태라는 점이다. 이를 보완하기 위해 Post-Busan 이행과정에서 보다 폭넓은 참여도출과 이행체제 구축에 대한 논의가 필요할 것이다.

\section{III. 우리나라 개발정책에 대한 함의}

\section{1. 우리나라의 적극적 역할 지속}

우리나라는 부산총회 준비과정에서 민간분야의 참여 제고를 위해 민간포럼 개최, 민간분야 비공식 작업반 참여 등 적극적인 역할을 해 수행함으로써 단순한 개최국의 역할을 넘어 민간분야 이슈가 글로 벌 개발협력 커뮤니티의 핵심이슈로 자리 잡는데 있어서 선도적 역할을 수행하였다. 특히, 민간포럼을 $\mathrm{UNDP}, \mathrm{OECD} \mathrm{BIAC}$ 및 국내적으로는 전경련, 유엔 글로벌 콤팩트 한국협회와 공동 개최함으로써 국 내외 포괄적인 민간분야간 협력 강화의 기반 마련에 크게 기여 하였다. 이러한 민간분야 이슈의 모멘 텀을 유지, 강화하기 위해서는 부산총회 민간분야 성과를 지속적으로 관리해나가는 것이 필요하다.

궁극적으로 우리 정부도 금번 부산 공동성명서의 정치적 의미를 지속적으로 부각시켜 나가면서 동시 에 보다 많은 주체가 공동성명에 참여할 수 있도록 파트너십 내실화에 관심을 기울여 나가야 할 것이다.

\section{2. 우리의 개발경험과 개도국 민간분야 지원과의 연계강화}

한국의 개발경험에서 민간분야 육성 및 경쟁력 강화를 위한 원조의 역할에 대한 연구 및 교훈을 보다 적극적으로 활용해 나갈 필요가 있을 것이다. 개발을 위한 Enabling environment 조성을 위한 민관 대화와 협력 경험을 향후 global partnership for development에 input으로 활용함으로써 민간 분야와의 광범위한 파트너십이 실질적인 개발임팩트를 확대하는데 기여하도록 해야 할 것이다.

\section{3. 민관파트너십 확대 강화 추진}

이번 부산총회에서의 큰 수확 중의 하나는 우리 민간분야의 개발에 대한 관심의 증가를 확인한 것 이라 할 수 있다. 종전 정부와의 별다른 협력없이 개도국 지원 프로그램을 운영하였던 많은 기업들이 민간파트너십의 틀에서 수원국 및 개도국 정부와의 긴밀한 협의를 통해 점차 상호간의 프로그램 연 
계를 도모하게 된 것은 개발성과 및 균등한 개발이라는 성과 도출에 매우 긍정적으로 하겠다.

아울러 우리 경제가 빠르게 성장하게 됨에 따라 우리 민간분야들이 글로벌 기업으로서의 사회적 책임 강화 필요를 인식하게 되었으며, 이는 한편으로 우리 기업의 글로벌 경쟁력 강화를 위한 기반으 로 작용할 수 있을 것으로 예상된다. 이러한 민간의 개발협력 활동 참여 제고를 위한 risk sharing 등 개발원조 활용한 효과적 민관 파트너십 확대 강화가 필요하다고 할 것이다. 이러한 맥락에서 볼 때 향후 우리의 개발협력 사업 효율화, 경쟁력 강화 과정에서 우리 민간 분야의 참여가 더욱 확대되 는 것이 필요할 것이며 이는 포괄적 개발파트너십, 다양한 개발이슈에 대한 개발임팩트 강화라는 부 산총회의의 목표와 이념 달성에 기여할 것으로 예상된다. 